PENANGGUNG JAWAB

Dekan Fakultas Ilmu Tarbiyah dan Keguruan

REVIEWER

Ani Cahyadi

Universitas Islam Negeri Antasari Banjarmasin, Indonesia

Imam Rofiki

Universitas Islam Negeri Maulana Malik Ibrahim Malang, Indonesia

Nuril Mufidah

Universitas Islam Negeri Maulana Malik Ibrahim Malang, Indonesia

Nuri Wuryandani

Universitas Negeri Yogyakarta, Indonesia

Muhammad Walid

Universitas Islam Negeri Maulana Malik Ibrahim Malang, Indonesia

Wahid Murni

Universitas Islam Negeri Maulana Malik Ibrahim Malang, Indonesia

EDITOR IN CHIEF

M. Irfan Islamy

Universitas Islam Negeri Maulana Malik Ibrahim Malang, Indonesia

SECTION EDITOR

Abdul Fattah

Universitas Islam Negeri Maulana Malik Ibrahim Malang, Indonesia

Galih Puji Mulyanto

Universitas Islam Negeri Maulana Malik Ibrahim Malang, Indonesia

Dewi Nur Suci

Sekolah Tinggi Agama Islam Kediri, Indonesia

Dwi Sulistiani

Universitas Islam Negeri Maulana Malik Ibrahim Malang, Indonesia

LAYOUT EDITOR

Rendi Setyo Marandi

Universitas Islam Negeri Maulana Malik Ibrahim Malang, Indonesia 
ii | P a g e

PEDOMAN TRANSLITERASI

\begin{tabular}{|c|c|c|c|}
\hline Arab & Latin & Arab & Latin \\
\hline 1 & $\mathrm{a}$ & ض & $\mathrm{dh}$ \\
\hline ب & b & b & th \\
\hline ت & $\mathrm{t}$ & ظ & zh \\
\hline ث & ts & $\varepsilon$ & I \\
\hline ج & $\mathrm{j}$ & $\dot{\varepsilon}$ & gh \\
\hline$\tau$ & h & ف & $\mathrm{f}$ \\
\hline$\dot{\tau}$ & kh & ق & $\mathrm{q}$ \\
\hline د & d & ك ك & $\mathrm{k}$ \\
\hline ذ & $\mathrm{dz}$ & J & 1 \\
\hline J & $r$ & م & $\mathrm{m}$ \\
\hline j & Z & ن & $\mathrm{n}$ \\
\hline س & $\mathrm{S}$ & 9 & W \\
\hline ش & sy & هـ & $\mathrm{h}$ \\
\hline ص & sh & ى & $\mathrm{y}$ \\
\hline
\end{tabular}


DAFTAR ISI

i

PENANGGUNG JAWAB

i

REVIEWER

i

EDITOR IN CHIEF

i

SECTION EDITOR

i

LAYOUT EDITOR

ii

PEDOMAN TRANSLITERASI

iii

DAFTAR ISI

01-12

Pembelajaran Bahasa Arab di MIN 13 Kabupaten Banjar Kalimantan Selatan

Mahmudah

Universitas Islam Negeri Antasari Banjarmasin, Indonesia

13-23

Keefektifan Model Make A Match dalam Pembelajaran Matematika Siswa Kelas VI

Sekolah Dasar di Kecamatan Marioriwawo

Andi Kaharuddin

Universitas Lakidende Unaaha, Indonesia

24-39

Konsepsi Penerapan Keterampilan Proses Sains (KPS) dan Sikap Ilmiah Dalam Desain Pengembangan Modul Panduan Eksperimen Ipa SD/MI

Ida Fiteriani ${ }^{1}$ dan Baharuddin ${ }^{2}$

1,2Universitas Islam Negeri Raden Intan Lampung, Indonesia

40-45

Pengembangan Multimedia Pembelajaran Interaktif Materi Pokok Sistem Tata Surya Untuk Siswa Kelas VI SD

Vannisa Aviana Melindaㄹ, Dimas Sambung'2, Dian Eka Aprilia Fitria Ningrum³ ${ }^{3}$ Imroatul Hayyu Erfantinni ${ }^{4}$, Roiyan One Febriani ${ }^{5}$

1,2,3,4,5Universitas Islam Negeri Antasari Banjarmasin Indonesia, Indonesia

46-52

Pengembangan Media Pembelajaran Pop-Up Berbasis Sains Kelompok B RA Raden Fatah Podorejo

Dessy Putri Wahyuningtyas ${ }^{1}$, Faizatun Na'fiah

1,2Universitas Islam Negeri Maulana Malik Ibrahim Malang, Indonesia

PEDOMAN PENULISAN

UCAPAN TERIMAKASIH

Vol. 11 No. 1, Desember 2018

Madrasah homepage: http://ejournal.uin-malang.ac.id/index.php/madrasah/index 


\title{
PENGEMBANGAN MULTIMEDIA PEMBELAJARAN INTERAKTIF MATERI POKOK SISTEM TATA SURYA UNTUK SISWA KELAS VI SD
}

\author{
Vannisa Aviana Melinda', Dimas Sambung2, Dian Eka Aprilia Fitria Ningrum³, Imroatul \\ Hayyu Erfantinni ${ }^{4}$, Roiyan One Febriani ${ }^{5}$ \\ Universitas Islam Negeri Maulana Malik Ibrahim Malang, Indonesia \\ 1vannisa1918@gmail.com, 2dimas.sambung@gmail.com, ${ }^{3}$ ningrumdianeka19@uin-malang.ac.id, \\ 4hayyu.erfantinni@uin-malang.ac.id, 5roiyan0102@gmail.com
}

\begin{abstract}
DOI: $10.18860 /$ madrasah.v11i1.6113
Abstrak. Tujuan dari penelitian dan pengembangan yaitu untuk menghasilkan suatu produk multimedia pembelajaran interaktif yang valid sehingga dapat digunakan sebagai sumber belajar yang efektif dan menarik untuk materi pokok sistem tata surya kelas VI SD. Model penelitian dan pengembangan yang digunakan diadaptasi dari model pengembangan multimedia Lee dan Owens. Pengembangan Multimedia pembelajaran interaktif divalidasi oleh 1 orang ahli media, 1 orang ahli materi serta pada ujicoba perorangan sebanyak 2 orang, kemudian sebanyak 4 orang untuk uji coba kelompok kecil dan 10 orang untuk uji lapangan. Setelah dilakukan metode analisis, hasil validasi multimedia pembelajaran interaktif ini dinyatakan valid dengan menyimpulkan hasil perhitungan ahli media, ahli materi dan siswa.
\end{abstract}

Kata kunci. Penelitian dan pengembangan; Multimedia Interaktif; Sistem Tata Surya; IPA; Sekolah Dasar

Abstrak. The objective of the research and development to produce a multimedia interactive learning product are valid so that it can be used as a learning resource that is effective and compelling subject matter for the solar system of elementary class VI. Research and development model used adapted from multimedia development Lee and Owens model. Multimedia interactive learning is validated by 1-person expert in material and 1-person expert in media, then individual tests by 2 people, small group of trials by 4 people and field test as many as 10 people. After the validation of results, the analysis method for multimedia interactive learning was declared valid by summing up the results of the calculations of experts, material and media students.

Keywords. Research and Development; Interactive Multimedia; The Solar System; Sains; Elementary

\begin{tabular}{ll|l}
\hline Received & :29 Agustus 2018 & Approved $: 30$ Desember 2018 \\
Reviesed & :30 Desember 2018 & Published $: 31$ Desember 2018 \\
\hline
\end{tabular}

Copyright (C) Madrasah Jurnal Pendidikan dan Pembelajaran Dasar. All Right Reserved.

This is an open access article under the CC BY-NC-ND license

(http://creativecommons.org/licenses/by-nc-nd/4.0/).

Correspondence Address: vannisa1918@gmail.com

\section{A. PENDAhUlUAN.}

Perkembangan teknologi saat ini juga berpengaruh pada pendidikan, terutama pada penggunaan media pembelajaran dalam proses pembelajaran. Memanfaatkan media pengajaran dalam proses pembelajaran akan lebih efektif dan mengurangi rasa jenuh. Ada banyak jenis media pembelajaran yang sudah digunakan untuk penyampaian informasi dan pembelajaran, Salah satu media yang digunakan adalah multimedia pembelajaran interaktif. Pemilihan multimedia interaktif dalam penelitian ini karena penggunaan tampilan multimedia interaktif yang dirancang oleh desainer sehingga terlihat memenuhi fungsi menginformasikan pesan dan memiliki lebih banyak aktivitas kepada pengguna (Munir, 2013:110). Fungsi multimedia interaktif ini sesuai dengan materi pelajaran tata surya pada kelas VI. 


\section{MADRASAH}

Jurnal Pendidikan dan Pembelajaran Dasar

p ISSN: 1979-5599 | e ISSN: 2502-194X

Page | 41

Menurut Rosch dalam Sutirman (2013:18) multimedia adalah kombinasi dari komputer dan video. Menurut Gayeski (dalam Munir 2013:2) "multimedia sebagai kumpulan media berbasis komputer dan sistem komunikasi yang memiliki peran untuk membangun, menyimpan, mengirim dan menerima informasi dalam bentuk teks, grafik, audio, video, dan sebagainya".

Multimedia interaktif juga dapat mengeksplorasi dalam dimensi yang tidak dapat dicapai di ruang kelas. Siswa dapat memperoleh beberapa konten audiovisual yang disinkronkan dengan slide presentasi, konten papan tulis, video, sehingga pembelajaran materi pelajaran tata surya dapat divisualisasikan. (Cattelan et al., 2008). Dalam pembelajaran, kadang-kadang diperlukan penggunaan presentasi slide yang dipadukan dengan papan tulis (Dicksonetal, 2012).

Untuk mengupayakan pembelajaran yang efektif diperlukan perencanaan dan perancangan yang secara sistematis dalam proses pembelajaran untuk pemanfaatan pembelajaran interaktif multimedia. Menurut Rosenberg (2001), dengan perkembangan teknologi informasi dan komunikasi ada lima pergeseran dalam proses pembelajaran, yaitu: (1) dari pelatihan ke penampilan, (2) dari ruang kelas ke berbagai tempat, (3) dari kertas ke "online", (4) dari fasilitas fisik ke jaringan, (5) dari waktu ke waktu.

\section{B. METODE PENELITIAN}

Model penelitian dan pengembangan yang digunakan dalam pengembangan multimedia interaktif diadaptasi dari model pengembangan multimedia Lee dan Owens. Tahapan model pengembangan multimedia Lee dan Owens dimulai dari tahap analisis dan penilaian, tahap desain, tahap pengembangan, tahap implementasi, dan tahap evaluasi yang dapat diuraikan sebagai berikut:

1. Analysis

a. Need Assessment, merupakan proses sistematis penetapan tujuan, dentifikasi kesenjangan antara kenyataan dengan kondisi yang diharapkan, dan menetapkan prioritas untuk kegiatan.

b. Front-End Analysis, merupakan sebuah teknik analisis data dan informasi yang sudah dikumpulkan untuk menentukan data dan informasi yang akan digunakan dari keseluruhan data yang diperoleh.

1) Analisis Audiens, bertujuan untuk mengetahui latar belakang, karakteristik dan keterampilan dari audiens yang akan menggunakan pembelajaran multimedia interaktif.

2) Analisis Teknologi, bertujuan untuk mengidentifikasi kemampuan teknologi yang dimiliki.

3) Analisis Situasi, bertujuan untuk mengidentifikasi kendala-kendala di dalam lingkungan belajar sehingga dapat digunakan sebagai pertimbangan dalam perancangan multimedia pembelajaran interaktif.

4) Analisis Tugas, merupakan proses menganalisis bagaimana siswa melaksanakan tugas, yaitu mempelajari perubahan kenampakan bumi dan perubahan kenampakan langit.

5) Analisis Isu, dalam analisis isu harus memeriksa tiga tingkat untuk memahami setiap masalah yaitu: organisasi, kinerja, pelatihan.

6) Analisis Tujuan, adalah tujuan yang telah ada dalam RPP.

7) Analisis Media, menganalisis multimedia pembelajaran interaktif yang dipilih.

8) Analisis Data, dilakukan untuk memecahkan masalah yang ditemui.

9) Analisis Biaya, dalam produksi multimedia pembelajaran interaktif.

Tahap selanjutnya adalah melakukan proses validasi ke ahli media, dan ahli materi setelah menyusun draft produk awal. Setelah data diperoleh selanjutnya dilakukan analisis untuk mengetahui hasil validasi dan sebagai acuan untuk melakukan revisi produk. Proses 
validasi akan dilakukan dengan subjek validasi yaitu: (1) desain uji coba, (2) subjek uji coba, (3) jenis data, (4) instrumen pengumpulan data, (5) teknik analisis data.

2. Desain Uji Coba

a. Uji coba satu persatu

1) Ahli media, validasi ahli media dilakukan oleh ahli media untuk memberi masukan dan tanggapan yang berkaitan dengan media yang dikembangkan. Pemilihan ahli media berdasarkan beberapa pertimbangan, yaitu memiliki keahlian di bidang multimedia dan memiliki latar belakang pendidikan minimal S1 bidang Teknologi Pendidikan.

2) Ahli materi, validasi ahli materi dilakukan oleh orang ahli materi untuk memberi masukan dan tanggapan yang berkaitan dengan materi yang dikembangkan, yaitu guru IPA SDN Bendosewu Talun Blitar.

3) Siswa (uji coba perorangan). Dilakukan oleh 2 orang siswa SDN Bendosewu Talun Blitar yang bertujuan untuk memberi masukan tentang produk yang dibuat.

b. Uji coba lapangan (uji coba siswa lebih luas)

1) Pengembang menjelaskan kepada siswa maksud melaksanakan uji coba.

2) Pengembang menyajikan multimedia interaktif untuk dipelajari siswa.

3) Pengembang mencatat umpan balik yang diberikan oleh siswa.

4) Pengembang memberikan angket kepada siswa agar berpendapat terhadap multimedia yang dipelajari.

5) Pengembang menganalisa angket dari siswa.

3. Subjek Coba

Subjek coba dalam pengembangan multimedia pembelajaran adalah siswa kelas VI SDN Bendosewu 2 Talun Blitar.

4. Jenis Data

Jenis data yang digunakan adalah kualitatif dan kuantitatif. Kualitatif merupakan tanggapan dari ahli media, ahli materi, siswa. Kuantitatif berupa skor hasil instrumen angket siswa.

5. Instrumen Pengumpulan Data

Instrumen yang digunakan adalah angket, angket digunakan sebagai:

a. Pengukur kelayakan multimedia pembelajaran.

b. Pengukur kesesuaian multimedia pembelajaran.

c. Pengumpul data tentang penilaian ahli media, ahli materi, dan siswa.

6. Teknik Analisis Data

Dalam menghitung data setiap item angket pengembangan yang menentukan penilaian yaitu Jawaban $A=4, B=3, C=2, D=1$

a. Rumus untuk mengolah data per item:

$P=\frac{X}{X i} x 100$ (Arikunto, 2010)

Keterangan:

$\mathrm{P} \quad=$ Persentase

$100 \%=$ Konstanta

$\mathrm{X}=$ Jumlah jawaban skor oleh subyek uji coba

$\mathrm{Xi} \quad=$ Jumlah jawaban maksimal

b. Rumus untuk mengolah data secara keseluruhan item 


\section{MADRASAH}

Jurnal Pendidikan dan Pembelajaran Dasar

$P=\frac{\sum X}{\sum X_{i}} x 100 \%$ (Arikunto, 2010)

Keterangan :

$\mathrm{P} \quad=$ Persentase

$\mathrm{X} \quad=$ Jumlah keseluruhan jawaban responden dalam seluruh item

$\mathrm{Xi} \quad=$ Jumlah keseluruhan nilai ideal dalam satu item

$100 \%=$ Konstanta

c. Interpretasi data

Setelah didapat hasil dari data dikelola dengan menggunakan rumus diatas maka hasil tersebut dicocokkan dengan kriteria tingkat kevalidan sebagai berikut :

Tabel B.1 Kriteria Tingkat Kelayakan

\begin{tabular}{cllcl}
\hline Kategori & \multicolumn{1}{c}{ Persentase } & \multicolumn{1}{c}{ Kualifikasi } & Nilai & \multicolumn{1}{c}{ Kriteria } \\
\hline A & $76 \%-100 \%$ & Valid & 4 & Valid \\
\hline B & $51 \%-75 \%$ & Cukup Valid & 3 & Cukup Valid \\
\hline C & $26 \%-50 \%$ & Kurang Valid & 2 & Kurang Valid \\
\hline D & $0 \%-25 \%$ & Tidak Valid & 1 & Tidak Valid \\
\hline
\end{tabular}

Keterangan kriteria tabel kelayakan:

1. Apabila media yang diuji cobakan tersebut mencapai tingkat prosentase $76 \%-100 \%$, maka media tersebut dikatakan kualifikasi valid.

2. Apabila media yang diuji cobakan tersebut mencapai tingkat prosentase $51 \%-75 \%$, maka media tersebut dikatakan kualifikasi cukup valid.

3. Apabila media yang diuji cobakan tersebut mencapai tingkat prosentase $26 \%-50 \%$, maka media tersebut dikatakan kualifikasi kurang valid.

4. Apabila media yang diuji cobakan tersebut mencapai tingkat prosentase $0 \%-25 \%$, maka media tersebut dikatakan kualifikasi tidak valid.

Produk Multimedia pembelajaran Ilmu Pengetahuan Alam kelas VI SD yang dikatakan berhasil dan layak apabila mencapai kriteria cukup valid (51\%-75\%) dan valid (76\%-100\%). Untuk mengolah hasil belajar siswa, teknik pengolahan data yang digunakan adalah:

$X=\frac{\sum f x}{N}$

Keterangan:

$\mathrm{X}$ : Skor rata-rata

: Jumlah penilitian antara frekuensi dengan skor

$\mathrm{N}$ : Jumlah siswa

Setelah didapatkan hasil dari data yang diolah dengan menggunakan rumus diatas. Maka hasil tersebut dicocokkan dengan kriteria ketuntasan minimum siswa dan kriteria tingkat keberhasilan siswa seperti dalam tabel berikut ini 
Tabel B.2 Kriteria Tingkat Keberhasilan Siswa

\begin{tabular}{cl}
\hline Score & Predicate \\
\hline $75 \%-100 \%$ & Berhasil \\
\hline $59 \%-74 \%$ & Cukup Berhasil \\
\hline$<49 \%$ & Gagal \\
\hline
\end{tabular}

\section{HASIL DAN PEMBAHASAN}

Berdasarkan pengolahan data ahli media, secara keseluruhan dapat diperoleh hasil persentase sebesar $91.25 \%$. Berdasarkan interpretasi data, termasuk dalam kriteria A dengan persentase $76 \%-100 \%$ maka multimedia interaktif yang dikembangkan tersebut termasuk dalam kualifikasi valid.

Berdasarkan pengolahan data ahli materi, secara keseluruhan dapat diperoleh hasil persentase sebesar $85 \%$. Berdasarkan interpretasi data, termasuk dalam kriteria A dengan persentase $76 \%-100 \%$ maka materi yang termuat dalam multimedia interaktif tersebut termasuk dalam kualifikasi valid.

Berdasarkan pengolahan data uji coba perorangan, secara keseluruhan dapat diperoleh hasil persentase sebesar $96.25 \%$. Berdasarkan interpretasi data, termasuk dalam kriteria A dengan persentase 76\%-100\% maka multimedia interaktif tersebut termasuk dalam kualifikasi valid.

Berdasarkan pengolahan data uji coba kelompok kecil, secara keseluruhan dapat diperoleh hasil persentase sebesar 88\%. Berdasarkan interpretasi data, termasuk dalam kriteria A dengan persentase 76\%-100\% maka multimedia interaktif tersebut termasuk dalam kualifikasi valid.

Berdasarkan pengolahan data uji lapangan, secara keseluruhan dapat diperoleh hasil persentase sebesar $89 \%$. Berdasarkan interpretasi data, termasuk dalam kriteria A dengan persentase $76 \%-100 \%$ maka multimedia interaktif tersebut termasuk dalam kualifikasi valid.

Hasil analisis tes hasil belajar setelah menggunakan multimedia pembelajaran tersebut menunjukan 14 siswa atau 87,5\% dan 2 siswa atau 12,5\% masih belum memahami materi. Yaitu dengan memenuhi KKM (Kriteria Ketuntasan Minimum) atau nilai diatas $\leq 75$.

\section{KESIMPULAN}

Dari data hasil belajar setelah penggunaan multimedia pembelajaran interaktif, dapat disimpulkan bahwa multimedia pembelajaran interaktif IPA Materi pokok sistem tata surya valid dan efektif digunakan dalam kegiatan pembelajaran.

\section{DAFTAR PUSTAKA}

Arikunto, S. (2010). Prosedur Penelitian: Suatu Pendekatan Praktek. Jakarta: PT Rineka Cipta.

Cattelan, R. G., Teixeira, C., Goularte, R., and Pimentel, M. D. G. C. (2008). Watch-and-comment as a paradigm toward ubiquitous interactive video editing. ACM Trans. Multimedia Comput. Commun. Appl., 4(4):28:1-28:24.

Dickson, P. E., Warshow, D. I., Goebel, A. C., Roache, C. C., and Adrion, W. R. (2012). Student reactions to classroom lecture capture. In Proc. ACM Annual Conference on Innovation and Technology in Computer Science Education, ITiCSE'12, pages144-149. ACM.

Lee, William W. and Owens Diana L. (2004). Multimedia-Based Instructional Design. San Francisco, USA: Pfeiffer, an imprint of Wiley.

Munir. (2013). Multimedia Konsep dan Aplikasi Dalam Pendidikan. Bandung: Alfabeta.

Rosenberg, Marc. J. (2001). E-Learning: Strategies for Delivering Knowledge in The Digital Age. 


\section{MADRASAH}

Jurnal Pendidikan dan Pembelajaran Dasar

p ISSN: 1979-5599 | e ISSN: 2502-194X

Page $\mid 45$

USA: McGraw-Hill Companies.

Sutirman. (2013). Media dan Model-model Pembelajaran Inovatif. Yogyakarta: Graha Ilmu. 


\section{PANDUAN PENULISAN \\ MADRASAH: JURNAL PENDIDIKAN DAN PEMBELAJARAN DASAR \\ FAKULTAS ILMU TARBIYAH DAN KEGURUAN \\ UNIVERSITAS ISLAM NEGERI MAULANA MALIK IBRAHIM MALANG}

\section{Umum}

1. Karya ilmiah harus asli, belum pernah dipublikasikan di media lain, atau sedang dalam proses review untuk diterbitkan di publikasi lain (melampirkan surat pernyataan).

2. Menggunakan Bahasa Indonesia atau Bahasa Inggris* (*Pastikan penulisan dengan Bahasa Inggris sesuai kaidah yang berlaku, dan disubmit online melalui http://ejournal.uin-malang.ac.id/index.php/madrasah, kami tidak bertanggung jawab jika artikel anda tidak mendapat respon dari reviewer)

3. Menggunakan kertas A4 $(21 \mathrm{~cm} \times 29.7 \mathrm{~cm})$, dengan margin kiri $2.5 \mathrm{~cm}, 2 \mathrm{~cm}$ kanan, $2 \mathrm{~cm}$ bawah, $2 \mathrm{~cm}$ atas.

4. Jumlah paper minimal 6 halaman, maksimal 16 halaman kecuali ada lampiran, toleransi maksimal 20 halaman dengan 1 spasi dan alignment justify.

5. Font yang digunakan Book Antiqua 12 pt dan Sakkal Majalla (Jika ada konten Bahasa Arab) 14 pt.

6. Disarankan menggunakan referensi yang terbaru 10 tahun terakhir, kecuali kitab klasik.

7. Format file menggunakan Mic. Office/open Office (disarankan office 2013/2016_ dengan eksistensi RTF bukan PDF.

\section{Kontent Naskah}

1. Judul maksimal 15 kata, alignment center.

2. Nama penulis tidak menggunakan gelar, mencantumkan institusi, dan email.

3. Abstrak minimal $150 \mathrm{kata}$ dan maksimal $300 \mathrm{kata}$, satu paragraph, tidak terdapat tabel dan gambar.

4. Keywords minimal 3 kata dan maksimal 5 kata, dipisahkan dengan tanda titik koma $(;)$.

5. Sistematika penulisan: Judul, Abstrak, Kata Kunci, Pendahuluan, Metode, Hasil, Pembahasan, Simpulan dan Saran, Pernyataan Terima Kasih (jika ada), Daftar Rujukan. Selain hasil riset, menyesuaikan dengan format penulis.

6. Format Tabel (Bold). Jika terdapat tabel, jarak antara row adalah 1 spasi, pada kategori tabel huruf ditebalkan (bold), dan penulisan sumber setelah tabel terakhir. Jika tabel bersambung ke halaman berikut blok row kategori tabel dengan kemudiak klik layout $=>$ repeat header rows seperti format tabel A.1.

Tabel A.1 Judul Tabel (justify)

(1 spasi)

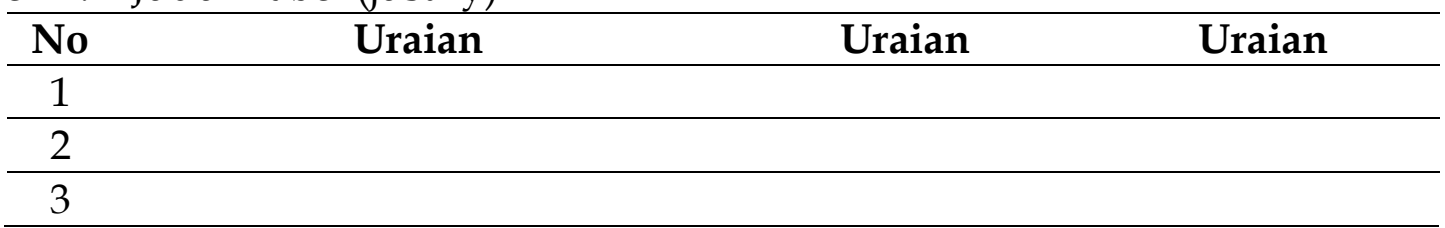

Sumber: 


\section{Format Gambar}

Jika terdapat gambar, grafik, diagram, dan yang serupa gunakan format dan wrap text gambar $=>$ in line with text atau menggunakan fitur text box, untuk kestabilan terhadap perubahan format dan pergesaran. Jarak antara kalimat terakhir dan sesudah gambar adalah 1 spasi. Gambar posisi center (tengah) seperti gambar A.1. (1 spasi)

Gambar A.1 Judul Gambar (center)

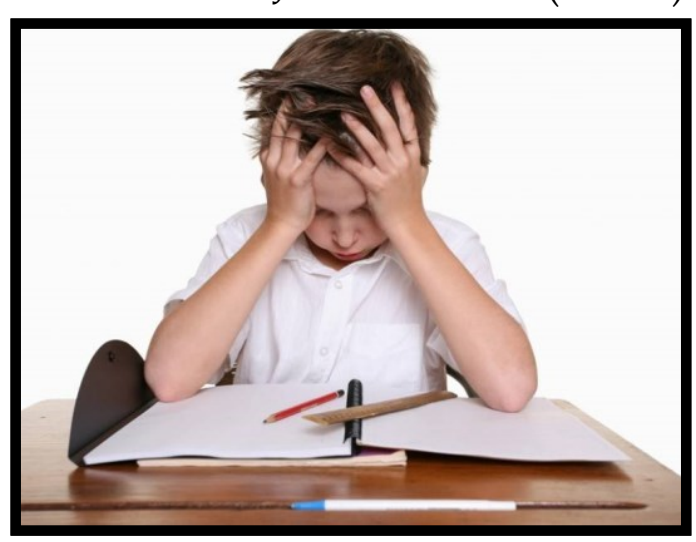

Sumber: (center)

(1 spasi)

\section{Format Numberring}

Pada jurnal Madrasah tidak diperkenankan menggunakan Bullet hanya Numberring, kecuali termasuk dalam penulisan rumus. Numbering menggunakan format Huruf dan Angka. Dimulai dari Huruf kemudian Angka seperti format berikut.

Format Numbering:

A.

1.

2.

a.

b.

1)

2)

a)

b)

B.

C.

9. Daftar Kutipan dan Rujukan menggunakan format APA 6 $^{\text {th }}$ Style Edition. Disarankan menggunakan aplikasi referensi seperti Zotero, Mandeley, Endnote, dan sebagainya.

10. Sebelum mengirim naskah, disarankan untuk melakuken cek typographical dan grammatical errors serta cek plagiat, bisa melalui.

a. Grammarly: www.grammarly.com 
b. Turnitin: http://turnitin.com/

11. Contatc:
a. Website : http://ejournal.uin-malang.ac.id/index.php/madrasah
b. Email : madrasah@uin-malang.ac.id
c. Editor in Chief: M. Irfan Islamy (085390790907)

\section{Author Fees}

This journal charges the following author fees.

Article Submission: 0 (IDR)

Fast-Track Review: 0 (IDR)

Article Publication: 0 (IDR)

Open Donations:

\section{Copyright Notice}

Madrasah: Jurnal Pendidikan dan Pembelajaran Dasar

\section{Privacy Statement}

The names and email addresses entered in this journal site will be used exclusively for the stated purposes of this journal and will not be made available for any other purpose or to any other party. 
UCAPAN TERIMAKASIH

KEPADA PARA REVIEWER, EDITOR, DAN PENULIS ATAS TERBITNYA MADRASAH: JURNAL PENDIDIKAN DAN PEMBELAJARAN DASAR VOLUME 11 NOMOR 1 DESEMBER 2018 